\title{
Amphetamine Activation of Hippocampal Drive of Mesolimbic Dopamine Neurons: A Mechanism of Behavioral Sensitization
}

\author{
Daniel J. Lodge and Anthony A. Grace \\ Departments of Neuroscience, Psychiatry, and Psychology, University of Pittsburgh, Pittsburgh, Pennsylvania 15260
}

\begin{abstract}
The repeated administration of psychostimulants induces an enhanced behavioral response to a subsequent drug challenge. This behavioral sensitization is proposed to model the increased drug craving observed in human psychostimulant abusers. Using in vivo extracellular recordings from identified ventral tegmental area dopamine (DA) neurons, we report that amphetamine-sensitized rats display an activation of ventral hippocampal neuron firing and a significantly greater number of spontaneously active DA neurons compared with saline-treated rats. Moreover, TTX inactivation of the ventral hippocampus restores DA neuron activity to control levels and also blocks the expression of locomotor sensitization. Taken as a whole, we propose that behavioral sensitization to psychostimulant drugs is attributable, at least in part, to persistent activation of the ventral hippocampus-nucleus accumbens pathway, with the resultant increase in tonic DA neuron firing enabling an abnormally higher response to subsequent psychostimulant administration.
\end{abstract}

Key words: hippocampus; VTA; amphetamine; sensitization; dopamine; drug abuse

\section{Introduction}

The repeated administration of psychostimulants such as cocaine and amphetamine induces an augmented response to a subsequent drug challenge (Segal and Mandell, 1974; Post and Rose, 1976). This is known as behavioral sensitization and is proposed to model the increased drug craving observed in human psychostimulant abusers (Robinson and Berridge, 1993). Given that the primary mechanism of action of psychostimulants is to enhance extracellular dopamine (DA), it is not surprising that there is considerable evidence demonstrating that behavioral sensitization is attributable, at least in part, to enhanced activity of the mesolimbic DA pathway (White and Wang, 1984; Henry et al., 1989; Kalivas and Stewart, 1991) (for review, see Pierce and Kalivas, 1997).

The activity of the mesolimbic DA system is regulated via two independent mechanisms: (1) transient or "phasic" DA release that is mediated mainly through DA neuron burst firing, and (2) extrasynaptic or "tonic" levels of DA that are mediated by basal DA neuron activity and regulated via presynaptic inputs (Grace, 1991; Floresco et al., 2003; Grace et al., 2007). Thus, it has been demonstrated that DA neuron burst firing induces a large transient increase in synaptic DA in target regions and is considered

Received Aug. 31, 2007; revised June 30, 2008; accepted June 30, 2008.

This work was supported by the United States Public Health Service Grants DA15408 and MH57440 (A.A.G.) and a Young Investigator Award from the National Alliance for Research on Schizophrenia and Depression-The Mental Health Research Association (D.J.L.). We thank Niki MacMurdo and Emily Mahar for their technical assistance and Brian Lowry for the production, development, and support with the custom-designed electrophysiology software (Neuroscope). We also acknowledge helpful discussions with Dr. Clint McCracken.

Correspondence should be addressed to Dr. Daniel J. Lodge, Department of Neuroscience, University of Pittsburgh, A210 Langley Hall, Pittsburgh, PA 15260. E-mail: lodge@pitt.edu.

DOI:10.1523/JNEUROSCI.1582-08.2008

Copyright $\odot 2008$ Society for Neuroscience $\quad$ 0270-6474/08/287876-07\$15.00/0 to be the temporally relevant signal sent to postsynaptic sites to encode reward prediction or indicate incentive salience (Berridge and Robinson, 1998; Schultz, 1998). In contrast, tonic DA transmission occurs over a much slower time scale and has been proposed to regulate the responsivity of the DA system through presynaptic and postsynaptic mechanisms (Grace, 1991; Lodge and Grace, 2006b; Grace et al., 2007).

One region that potently modulates DA neuron activity is the ventral hippocampus (vHipp) (Legault and Wise, 1999; Floresco et al., 2003; Lodge and Grace, 2006b), a temporal lobe structure involved in memory formation as well as the processing of novel and contextual information (Moses et al., 2002; Squire et al., 2004). vHipp activation increases DA neuron population activity (i.e., the number of DA neurons firing spontaneously) that is correlated with significant increases in extracellular DA levels in the nucleus accumbens (Acb) (Floresco et al., 2003). Furthermore, the hippocampus itself receives a significant input from the ventral tegmental area (VTA), and it has been demonstrated that DA acts to modulate hippocampal plasticity and subsequently learning and memory (Frey et al., 1990, 1991; Matthies et al., 1997; Lisman and Grace, 2005; Granado et al., 2008). Thus, longterm potentiation (LTP), an index of synaptic strength and prominent form of signaling in the hippocampus, is strongly dependent on DA. More specifically, late-phase LTP is blocked by dopamine $\mathrm{D}_{1}$ receptor antagonists and is absent in $\mathrm{D}_{1}$ receptor knock-out mice, whereas $\mathrm{D}_{1}$ receptor activation leads to an enhancement of hippocampal LTP (Frey et al., 1990, 1991; Matthies et al., 1997; Granado et al., 2008).

The expression of behavioral sensitization to psychostimulants has consistently been shown to be significantly more robust when the sensitizing drug injections are performed in the same environmental context as that used for the drug challenge (Hin- 
son and Poulos, 1981; Post et al., 1981; Badiani et al., 1995). Given the critical role of the vHipp in the processing of contextual information and in the regulation of DA neuron activity states, we propose that repeated psychostimulant administration induces a hippocampal hyperfunction and subsequent increase in tonic DA neuron activity that is the cause of the augmented phasic DA response to subsequent psychostimulant administration. The current studies were designed to test this hypothesis.

\section{Materials and Methods}

All experiments were performed in accordance with the guidelines outlined in the United States Public Health Service Guide for the Care and Use of Laboratory Animals and were approved by the Institutional Animal Care and Use Committee of the University of Pittsburgh.

Acute studies. Male Sprague Dawley rats (300-400 g) were housed individually in plastic breeding tubs and injected daily for $5 \mathrm{~d}$ (between 3:00 and 5:00 P.M.) with either D-amphetamine sulfate $(1.5 \mathrm{mg} / \mathrm{kg} / \mathrm{d}$, i.p.) or saline $(1 \mathrm{ml} / \mathrm{kg} / \mathrm{d}$, i.p.). Given that all electrophysiology is performed in anesthetized animals, the home cage is the environmental context for these studies. After a $5 \mathrm{~d}$ drug-free period, rats were anesthetized with chloral hydrate $(400 \mathrm{mg} / \mathrm{kg}$, i.p.) and placed in a stereotaxic apparatus. Anesthesia was maintained by supplemental administration of chloral hydrate as required to maintain suppression of limb compression withdrawal reflex. A core body temperature of $37^{\circ} \mathrm{C}$ was sustained by a thermostatically controlled heating pad. For acute administration of drugs into the vHipp, rats were implanted with a 23 gauge cannula 2.0 $\mathrm{mm}$ dorsal to the vHipp [anteroposterior $(\mathrm{A} / \mathrm{P})-6.0$, mediolateral $(\mathrm{M} / \mathrm{L})+5.3$, dorsoventral $(\mathrm{D} / \mathrm{V})-4.5 \mathrm{~mm}$ from bregma] that was fixed in place with dental cement and two anchor screws. Chemical inactivation was performed with tetrodotoxin (TTX; $1 \mu \mathrm{M}$ ) infused in a volume of $0.5 \mu \mathrm{l}$ through a 30 gauge injection cannula protruding $2.0 \mathrm{~mm}$ past the end of the implanted guide cannula. Dulbecco's PBS $(0.5 \mu \mathrm{l})$ was infused into the vHipp for control experiments. The injection cannula was left in situ for 1-2 min to ensure diffusion of drug into the surrounding tissue. Tetrodotoxin $(1 \mu \mathrm{m} / 0.5 \mu \mathrm{l})$ was injected at a dose previously reported to induce specific neurochemical effects (Floresco et al., 2001; Lodge and Grace, 2007). Rats received only one injection per region, and DA neuron activity was typically recorded from $10 \mathrm{~min}$ to $2 \mathrm{~h}$ after infusions. A group of untreated control rats were administered amphetamine (1.5 $\mathrm{mg} / \mathrm{kg}$, i.p.) immediately preceding dopamine neuron recordings to examine the acute effects of amphetamine administration.

VTA DA neuron extracellular recordings. Extracellular microelectrodes (impedance 6-14 M $\Omega$ ) were lowered into the VTA (A/P - 5.3, M/L + 0.8 $\mathrm{mm}$ from bregma and -6.5 to $-9.0 \mathrm{~mm}$ ventral of brain surface) using a hydraulic microdrive, and the activity of the population of DA neurons was determined by counting the number of spontaneously active DA neurons encountered while making six to nine vertical passes, separated by $200 \mu \mathrm{m}$, in a predetermined pattern to sample equivalent regions of the VTA. Spontaneously active DA neurons were identified with open filter settings (low pass, $50 \mathrm{~Hz}$; high pass, $16 \mathrm{kHz}$ ) using previously established electrophysiological criteria (Grace and Bunney, 1983; Grace et al., 2007), and once isolated, their activity was recorded for 2-3 min. Three parameters of activity were measured: (1) population activity (defined as the number of spontaneously active DA neurons recorded per electrode track), (2) basal firing rate, and (3) the proportion of action potentials occurring in bursts [defined as the occurrence of two spikes with an interspike interval of $<80 \mathrm{~ms}$, and the termination of the burst defined as the occurrence of an interspike interval of $>160 \mathrm{~ms}$ (Grace and Bunney, 1984)].

$v$ Hipp neuron extracellular recordings. Extracellular microelectrodes (impedance 10-14 M $\Omega$ ) were lowered into the vHipp (A/P -5.0, M/L $+4.5 \mathrm{~mm}$ from bregma and -5.5 to $-8.5 \mathrm{~mm}$ ventral of brain surface) using a hydraulic microdrive. vHipp neuron activity was examined by making seven to eight vertical passes, separated by $200 \mu \mathrm{m}$, in a predetermined pattern to sample equivalent regions of the vHipp. Once isolated, spontaneously active vHipp neurons were recorded for $3 \mathrm{~min}$. Four parameters of activity were measured: (1) average firing rate, (2) the proportion of action potentials occurring in bursts (defined as the occur- rence of two spikes with an interspike interval of $<50 \mathrm{~ms}$ ), (3) interspike interval within burst, and (4) the average number of spikes per burst.

Acb field potential recordings. Hippocampal-evoked Acb field recordings were performed essentially as reported previously (Goto and Grace, 2005b). In brief, bipolar concentric stimulating electrodes were placed in the vHipp (A/P +5.3, M/L +5.0, and $-8.0 \mathrm{~mm}$ ventral from bregma) and dorsal medial prefrontal cortex (mPFC; $\mathrm{A} / \mathrm{P}+3.2, \mathrm{M} / \mathrm{L}+0.5$, and $-3.0 \mathrm{~mm}$ ventral from bregma). In vivo evoked local field potential responses were examined using low-impedance glass microelectrodes $(4-6 \mathrm{M} \Omega)$ lowered into the Acb $(\mathrm{A} / \mathrm{P}+1.4, \mathrm{M} / \mathrm{L}+1.4 \mathrm{~mm}$ from bregma and $-7.5 \mathrm{~mm}$ ventral of brain surface). The field potential signal was amplified $(1000 \times)$, filtered (low pass, $1 \mathrm{~Hz}$; high pass, $1 \mathrm{kHz}$ ), and digitized $(10 \mathrm{kHz})$ for off-line analysis. Isolated current pulses $(0.25 \mathrm{~ms}$, $0.2-0.5 \mathrm{~mA}$ ) were delivered to the vHipp at a rate of $0.1 \mathrm{~Hz}$ and current intensity adjusted to evoke a submaximal $(\sim 50 \%)$ local field potential (LFP) response. There were no significant differences in the current intensity required to induce a submaximal response between saline- and amphetamine-treated rats. After a 20 min equilibration, 20 min of baseline evoked LFPs were recorded before high-frequency stimulation of the vHipp ( $3 \times 50 \mathrm{~Hz}$ trains, $1 \mathrm{~mA}$, $2 \mathrm{~s}$ train duration, 0.05 trains/s). Evoked LFPs were recorded for $40 \mathrm{~min}$ before high-frequency stimulation of the $\mathrm{mPFC}(3 \times 50 \mathrm{~Hz}$ trains, $1 \mathrm{~mA}, 2 \mathrm{~s}$ train duration, 0.05 trains/s). vHipp evoked LFPs were recorded for a further $40 \mathrm{~min}$. This technique has been characterized previously and demonstrated to induce robust plastic changes in Acb responsivity (Goto and Grace, 2005a,b).

Behavioral sensitization to amphetamine. All survival surgical procedures were performed under general anesthesia in a semisterile environment. Briefly, male rats were anesthetized with ketamine/xylazine (80/12 $\mathrm{mg} / \mathrm{kg}$, i.p., respectively) and placed in a stereotaxic apparatus using blunt atraumatic ear bars. Bilateral cannulas ( $23 \mathrm{ga})$ were implanted 2 $\mathrm{mm}$ dorsal to the ventral hippocampus (A/P -6.0, M/L $\pm 5.3, \mathrm{D} / \mathrm{V}-4.5$ $\mathrm{mm}$ from bregma) and fixed in place with dental cement and four anchor screws. Once the cement was completely solid, the wound was sutured, and the rat was removed from the stereotaxic frame and monitored closely until conscious. Rats received antibiotic treatment (gentamicin 3 $\mathrm{mg} / \mathrm{kg}$, s.c.) and postoperative analgesia (Children's Tylenol syrup in softened rat chow; $5 \% \mathrm{v} / \mathrm{w}$ ) ad libitum for $48 \mathrm{~h}$. Rats were housed with a reverse light/dark cycle (lights on 7:00 P.M. to 7:00 A.M.) for at least 2 weeks before behavioral experiments. A timeline for the behavioral experiments is presented in Figure 1. Briefly, on day 0, rats were acclimatized to an open-field arena (Coulbourn Instruments) where spontaneous locomotor activity in the $X-Y$ plane was monitored for $120 \mathrm{~min}$ by beam breaks and recorded with TruScan software (Coulbourn Instruments). On days $1-5$, rats were treated with either amphetamine (1.5 $\mathrm{mg} / \mathrm{kg}$, i.p.) or saline ( $1 \mathrm{ml} / \mathrm{kg}$, i.p.), and the expression of locomotor activity was recorded in an open-field arena. For days 6-10, rats remained drug-free in their home cages. On testing day 11, rats were administered intra-vHipp TTX ( $1 \mu \mathrm{M})$ or vehicle (Dulbecco's PBS) bilaterally $(0.5 \mu \mathrm{l} /$ side $)$ and placed in the open-field arena for $30 \mathrm{~min}$. All rats were then administered a challenge dose of amphetamine $(1.5 \mathrm{mg} / \mathrm{kg}$, i.p.), and locomotor activity was recorded for an additional $90 \mathrm{~min}$. It should be noted that locomotor activity was examined during the active part of the diurnal cycle, whereas DA recordings were performed during the inactive part of the cycle. Importantly, recent data have demonstrated that DA neurons do not display differences in firing across the diurnal cycle (Luo et al., 2008).

Histology. At the cessation of the electrophysiology experiments, the recording site was marked via electrophoretic ejection of Pontamine sky blue from the tip of the recording electrode $(-25 \mu \mathrm{A}$ constant current for $20-30 \mathrm{~min}$ ), and stimulating electrodes were marked by passing constant current across the poles $(10 \mathrm{~s}, 0.3 \mathrm{~mA})$. For acute studies, rats were killed by an overdose of anesthetic (chloral hydrate, additional $400 \mathrm{mg} / \mathrm{kg}$, i.p.), whereas for repeated drug studies, rats were killed by a lethal dose of anesthetic (sodium pentobarbital, $120 \mathrm{mg} / \mathrm{kg}$, i.p.). All rats were decapitated, and their brains were removed, fixed for at least $48 \mathrm{~h}(8 \% \mathrm{w} / \mathrm{v}$ paraformaldehyde in PBS), and cryoprotected (25\% w/v sucrose in PBS) until saturated. Brains were sectioned (60 $\mu \mathrm{m}$ coronal sections), mounted onto gelatin-chrome alum-coated slides and stained with cresyl violet for histochemical verification of electrode and/or cannula sites. 
The locations of drug infusion cannulas in the vHipp are presented in Figure 2. All histology was performed with reference to a stereotaxic atlas (Paxinos and Watson, 1986).

Analysis. Electrophysiological analysis of single-unit neuron activity and evoked Acb LFPs were performed using custom-designed computer software (Neuroscope). The magnitude of the LFP was determined as the difference (in millivolts) between $\mathrm{P} 1$ and N1, and data were averaged across 2 min periods (see Fig. $4 A$ ). Locomotor behavior was recorded using TruScan software (Coulbourn Instruments). All data are represented as the mean \pm SEM unless otherwise stated. All statistics were calculated using the SigmaStat software program (Jandel).

Materials. Ketamine $\mathrm{HCl}$ and xylazine were of United States Pharmacopeia (USP) grade and purchased from Phoenix Pharmaceutical, and pentobarbital sodium (USP) was obtained from Ovation Pharmaceuticals. Chloral hydrate, tetrodotoxin, gentamicin solution, Dulbecco's PBS, and D-amphetamine sulfate were all purchased from Sigma. All other chemicals and reagents were of either analytical or laboratory grade and purchased from various suppliers.

\section{Results}

Using in vivo extracellular recordings from identified DA neurons in chloral hydrate-anesthetized rats, we examined the effect of acute and repeated amphetamine administration on DA neuron activity states in the VTA [see timeline (Fig. 1)]. Rats that received daily saline injections ( $n=6$ rats, 48 neurons) exhibited an average of $1.13 \pm 0.07$ spontaneously active DA neurons per electrode track that fired at an average rate of $4.54 \pm 0.27 \mathrm{~Hz}$ and with $26.8 \pm 3.7 \%$ of the action potentials occurring in a burst discharge pattern (Fig. $3 a-c$ ); this is consistent with previous findings in untreated rats (Floresco et al., 2003; Lodge and Grace, $2006 \mathrm{a}, \mathrm{b})$. Acute amphetamine administration $(n=7$ rats, 31 neurons) resulted in a significant decrease in DA neuron population activity $(0.50 \pm 0.05$ cells per track; $p<0.05$, one-way ANOVA, Student-Newman-Keuls post hoc) (Fig. 3a). No significant differences were observed in burst firing $(26.2 \pm 5.2 \%)$ or average firing rate $(3.65 \pm 0.33 \mathrm{~Hz})$ across the population of neurons recorded; however, a shift in the firing rate frequency distribution was observed after acute amphetamine administration (Fig. $3 d$ ). In contrast, repeated ( $5 \mathrm{~d}$ ) amphetamine administration followed by $5 \mathrm{~d}$ withdrawal ( $n=7$ rats, 79 neurons) resulted in a significant increase in DA neuron population activity $(1.78 \pm 0.09$ cells per track; $p<0.05$, one-way ANOVA, Student-Newman-Keuls post hoc) (Fig. $3 a$ ) relative to control and acute amphetamine, without significantly affecting average burst firing $(24.5 \pm 3.0 \%)$ or firing rate $(4.42 \pm 0.20 \mathrm{~Hz})$ (Fig. $3 b, c)$. It should be noted that the increased number of cells observed after repeated amphetamine treatment was not localized to a specific subregion of the VTA.

Previous studies showed that VTA DA neuron population activity is controlled by activity within the vHipp, via a vHippAcb-ventral pallidum-VTA pathway (Floresco et al., 2001, 2003), and that abnormally high activity in this region can augment the behavioral response to amphetamine (Lodge and Grace, 2007). Thus, we examined the activity of vHipp neurons after repeated amphetamine treatment. Rats that received daily saline injections ( $n=5$ rats, 65 neurons) exhibited an average firing rate of $0.52 \pm 0.07 \mathrm{~Hz}$ with $32.5 \pm 3.0 \%$ of the action potentials
Figure 1. Experimental timeline. E-Phys, Electrophysiology.

occurring in a burst discharge pattern, an average within-burst interspike interval (ISI) of $14.6 \pm 1.3 \mathrm{~ms}$, and $2.29 \pm 0.07$ spikes per burst, consistent with previous findings (Lodge and Grace, 2007). Repeated ( 5 d) amphetamine administration followed by $5 \mathrm{~d}$ withdrawal ( $n=5$ rats, 45 neurons) resulted in a significant increase in the average firing rate of vHipp neurons $(1.40 \pm 0.07$ $\mathrm{Hz} ; p<0.05$, Mann-Whitney rank sum test), an increase in both the percentage ( $41.8 \pm 3.0 \%$; $p<0.05$, Mann-Whitney rank sum test) and number of spikes per burst $(2.44 \pm 0.08$; $p<0.05$, Mann-Whitney rank sum test), relative to control, without significantly affecting the within-burst ISI (14.7 $\pm 1.4 \mathrm{~ms})$.

Because the occlusion of plasticity in the vHipp-Acb pathway has been previously demonstrated after cocaine sensitization (Goto and Grace, 2005b), we examined the induction and reversal of LTP after repeated amphetamine treatment. Consistent with previous data in untreated rats, high-frequency stimulation of the vHipp induced an enhanced local field potential response in the vHipp-Acb pathway, a process that was attenuated by high-frequency stimulation of the dorsal mPFC (Fig. 4b) (Goto and Grace, 2005b). In contrast to that observed after cocaine sensitization, repeated amphetamine administration had no significant effect on vHipp-Acb plasticity after vHipp tetanus; however, the ability of high-frequency stimulation of the dorsal mPFC to attenuate this vHipp-Acb LTP was diminished in the amphetamine-sensitized rats (Fig. 4c).

Our studies show that repeated amphetamine administration causes an abnormal activation of the vHipp and an altered regulation of the vHipp-Acb projection. Given the role of the vHipp in the regulation of DA neuron population activity, and the context-dependent nature of behavioral sensitization, we examined whether attenuation of this aberrant vHipp activity in amphetamine-sensitized rats could restore VTA DA neuron activity states to control levels. Thus, intra-vHipp administration of the sodium channel blocker TTX to amphetamine-sensitized rats ( $n=8$ rats, 58 neurons) significantly attenuated the augmented population activity observed in sensitized rats $(1.08 \pm 0.16$ cells per track; $p<0.05$, one-way ANOVA, Student-Newman-Keuls post hoc) (Fig. $5 a$ ). Importantly, blockade of hippocampal transmission with TTX did not significantly alter any parameter of DA neuron activity in control rats ( $n=6$ rats, 47 neurons; population activity, $1.04 \pm 0.05$ cells per track; firing rate, $4.95 \pm 0.27 \mathrm{~Hz}$; 
Acute Expts

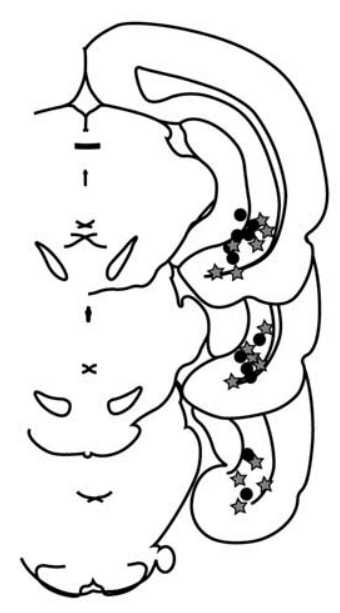

Behavioral Expts

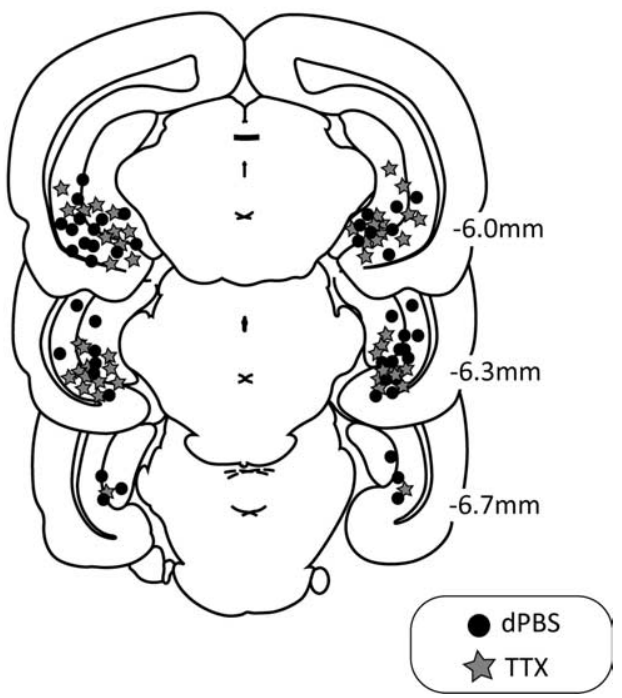

Figure 2. Histological localization of injection sites within the vHipp. Numbers beside each plate represent approximate A/P distance from bregma. dPBS, Dulbecco's PBS; Expts, experiments.

A

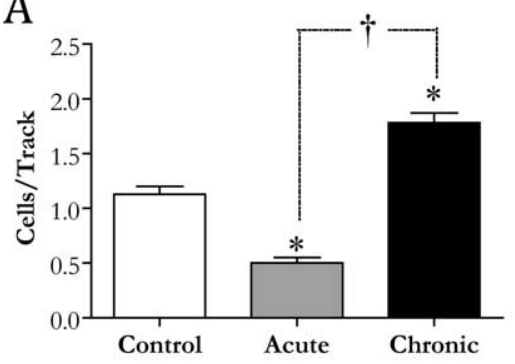

C

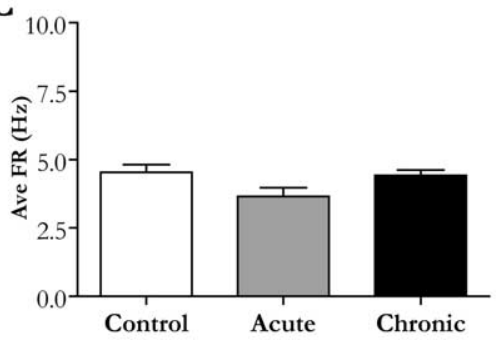

B

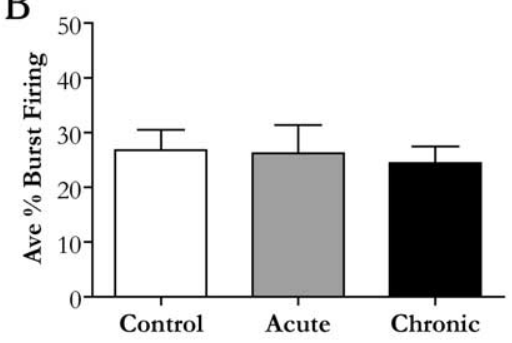

D

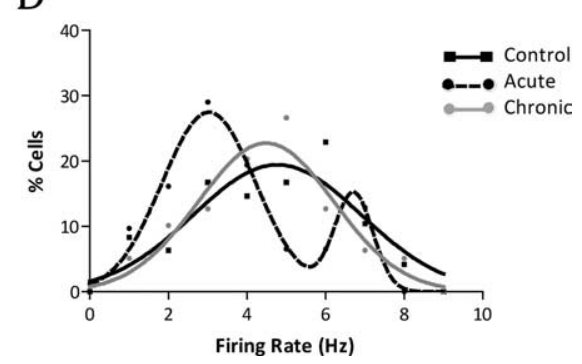

Figure 3. Repeated amphetamine administration increases tonic DA neuron population activity. $\boldsymbol{A}-\boldsymbol{D}$, Four parameters of activity were recorded: population activity (number of spontaneously firing DA neurons per electrode track; $\boldsymbol{A}$ ), average (Ave) percentage spikes fired in bursts $(\boldsymbol{B})$, average firing rate (FR; $\boldsymbol{C}$, and firing rate frequency distribution $(\boldsymbol{D})$. Acute amphetamine administration $(1.5 \mathrm{mg} / \mathrm{kg}$, i.p.) resulted in a significant decrease in population activity, whereas a significantly higher population activity was observed after repeated amphetamine administration. No significant differences were observed in burst firing or average firing rate; however, a shift in the firing rate frequency distribution is observed after acute amphetamine. *Statistically significant difference from control (repeated saline administration); ${ }^{\dagger}$ statistically significant difference between acute and repeated amphetamine treatment ( $p<0.05,1$-way ANOVA, Student-Newman-Keuls post hoc; $n=6-7$ rats per group; error bars represent SEM).

burst firing, $31.2 \pm 4.2 \%$ ) (Fig. $5 a-c$ ), nor did it significantly affect firing rate $(4.23 \pm 0.27 \mathrm{~Hz})$ or burst firing $(28.8 \pm 3.9 \%)$ in amphetamine-sensitized rats (Fig. $5 b, c$ ).

Given the recent literature correlating increased vHipp activity with an augmented behavioral responsivity to amphetamine (White et al., 2006; Lodge and Grace, 2007), we tested whether behavioral sensitization may be attributable to aberrant vHipp activity. Consistent with previous observations, repeated am- phetamine administration induced an augmented locomotor response to an amphetamine challenge compared with saline-treated rats (Fig. $6 a$ ). Furthermore, whereas bilateral hippocampal inactivation had no significant effect on amphetamine-induced locomotor activity in control animals (Fig. 6b), it significantly reversed the augmented psychostimulantinduced locomotion observed in amphetamine-sensitized rats (Fig. 6c).

\section{Discussion}

The data presented here demonstrate that behavioral sensitization to amphetamine is attributable, at least in part, to an enhanced mesolimbic DA neuron drive, secondary to augmented activity in the vHipp. This enhanced DA neuron drive is expressed as an increased population activity, i.e., the number of spontaneously active DA neurons. Furthermore, this enhancement is not attributable to the acute pharmacological effects of amphetamine, because acute psychostimulant administration produces the opposite response, i.e., a decrease in the number of spontaneously active DA neurons (Fig. 3) (Lodge and Grace, 2005) as a result of augmented somatodendritic DA-mediated autoinhibition and feedback inhibition from forebrain structures (Einhorn et al., 1988).

An association between hippocampal activity and ascending DA function has been suggested previously (Legault and Wise, 1999; Floresco et al., 2001, 2003; Lodge and Grace, 2006b, 2007). Thus, the vHipp can modulate DA neuron population activity and Acb DA overflow via a multisynaptic (vHipp-Acb-ventral pallidal-VTA) pathway (Floresco et al., 2001, 2003). Furthermore, NMDA activation of the vHipp augments the locomotor response to intra-Acb amphetamine (White et al., 2006). We now demonstrate that repeated amphetamine administration can result in aberrant DA neuron signaling and suggest that this is secondary to enhanced activity in the vHipp. Specifically, we demonstrate that repeated amphetamine-treated rats display a significantly higher number of spontaneously active DA neurons compared with control rats, consistent with previous observations (White and Wang, 1984; Henry et al., 1989). Such an increase in DA neuron population activity would enhance the tone of the DA system and result in an augmented DA response to subsequent psychostimulant administration. Furthermore, increased DA neuron population activity is also able to regulate phasic DA neuron responses by increasing the number of DA neurons available to convey a phasic signal (Lodge and Grace, 2006b). Because phasic DA neuron activity 

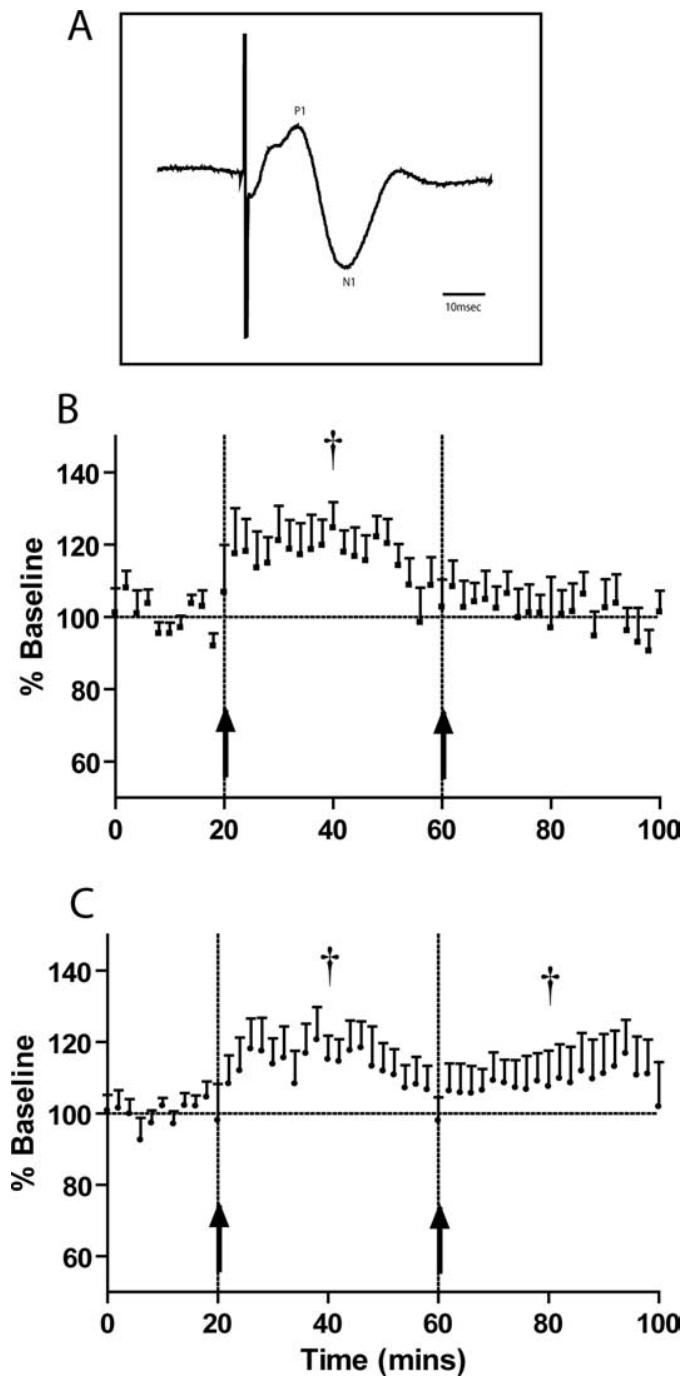

Figure 4. $\quad$ vHipp-Acb plasticity is unchanged after amphetamine sensitization. $\boldsymbol{A}$, Average vHipp evoked local field potential waveform recorded in the Acb (average of 200 sweeps). P1 and $\mathrm{N} 1$ refer to the first positive and negative peaks, respectively. $\boldsymbol{B}$, Saline-treated rats display an increased LFP response after high-frequency stimulation of the vHipp (first arrow). This is attenuated after high-frequency stimulation of the dorsal $\mathrm{mPFC}$ (second arrow). C, A similar LTP is observed in amphetamine-treated rats after high-frequency stimulation of the vHipp; however, this is not significantly attenuated after tetanic stimulation of the mPFC. Significant group difference in normalized data relative to baseline $\left({ }^{\dagger} p<0.05\right.$, ANOVA on ranks, Dunn's post hoc; $n=9$ rats per group; error bars represent SEM).

is highly correlated with reward prediction (Schultz, 1998), such an altered phasic signal would likely result in aberrant reward processing.

Given the context-dependent nature of behavioral sensitization and the critical role of the vHipp in the processing of contextual information, we examined whether aberrant hippocampal activity may be responsible for the augmented DA neuron population activity in amphetamine-sensitized rats. Recordings within the vHipp demonstrated that, in amphetamine-sensitized rats, there was a significant increase in baseline activity of the vHipp. Given that the baseline firing rate of vHipp neurons is similar in the awake and anesthetized rats (Jung et al., 1994), we believe that this threefold increase in vHipp activity is sufficient to alter information processing in the Acb. Furthermore, the ability of the $\mathrm{MPFC}$ to regulate vHipp-Acb drive was significantly attenuated. Thus, after amphetamine sensitization, the mPFC
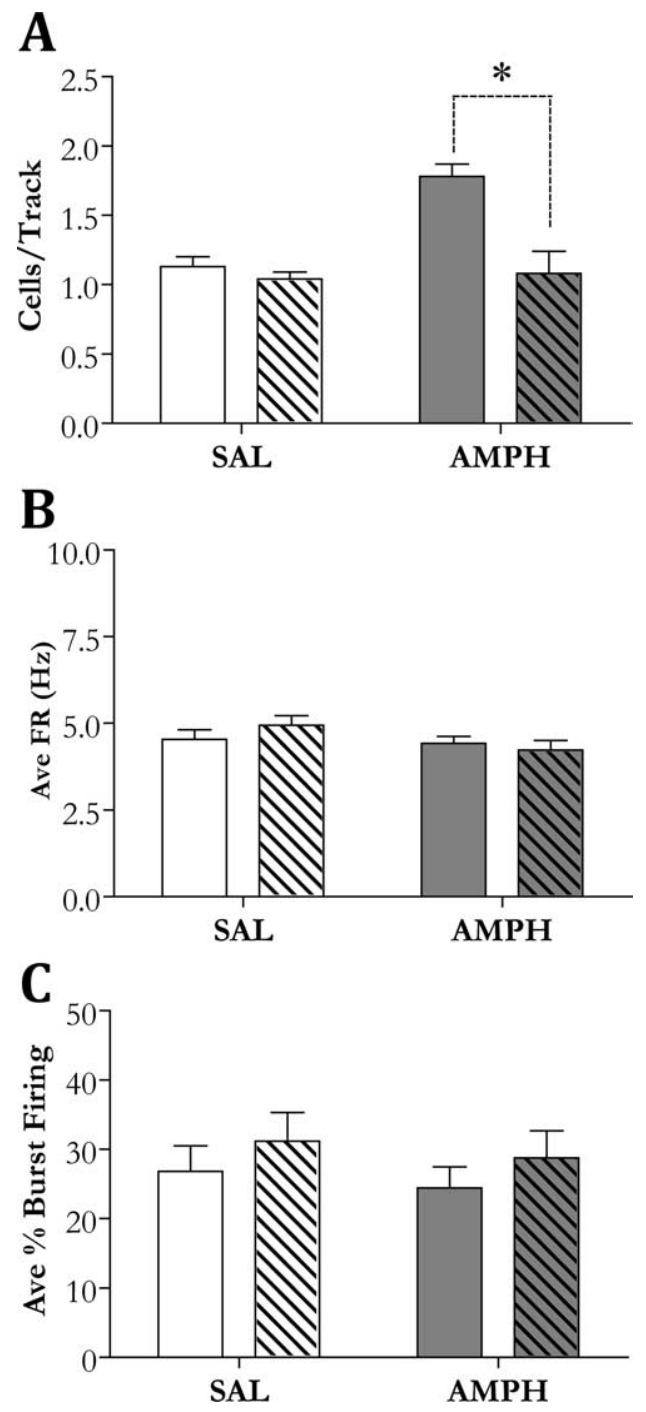

Figure 5. $\quad A-C$, Inactivation of the vHipp by TTX (1 $\mu \mathrm{m}$; hatched bars) normalizes the aberrant increase in DA neuron population activity in amphetamine-sensitized rats $(\mathrm{AMPH} ; A)$, while having no observable effect in control rats [saline-treated (SAL); white bars] or on any other DA neuron activity state $(\boldsymbol{B}, \boldsymbol{C})$ in sensitized rats (gray bars). Significant difference between vehicle and vHipp inactivated rats $\left({ }^{*} p<0.05\right.$, 1-way ANOVA, Student-Newman-Keuls post hoc; $n=$ $6-8$ rats per group; error bars represent SEM). Ave, Average; FR, firing rate.

loses the ability to reset this system to baseline levels. Inactivation of this aberrant vHipp drive via TTX inactivation of the vHipp normalized the increased DA neuron population activity to a level consistently observed in control animals. This manipulation had no significant effect on any other parameter of DA neuron activity in rats repeatedly treated with amphetamine, nor did it have any observable effects on DA neuron activity in control animals. Furthermore, given that chemical enhancement of vHipp output augments the locomotor response to amphetamine (White et al., 2006), we propose that the behavioral sensitization to repeated amphetamine administration may be attributed to vHipp-induced enhancement of baseline DA neuron population activity. Indeed, bilateral hippocampal inactivation significantly reduced the augmented psychostimulant-induced locomotion observed in amphetamine-treated rats back to that observed in controls, while having no significant effect on amphetamine-induced locomotor activity in control animals. It is important to note that there were no differences in baseline 
A

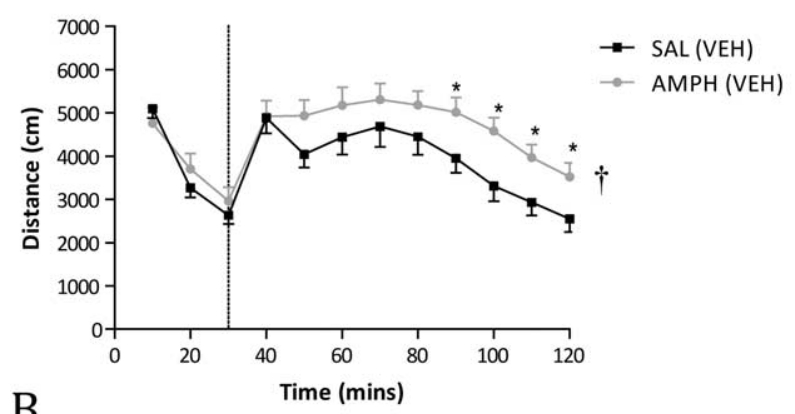

B
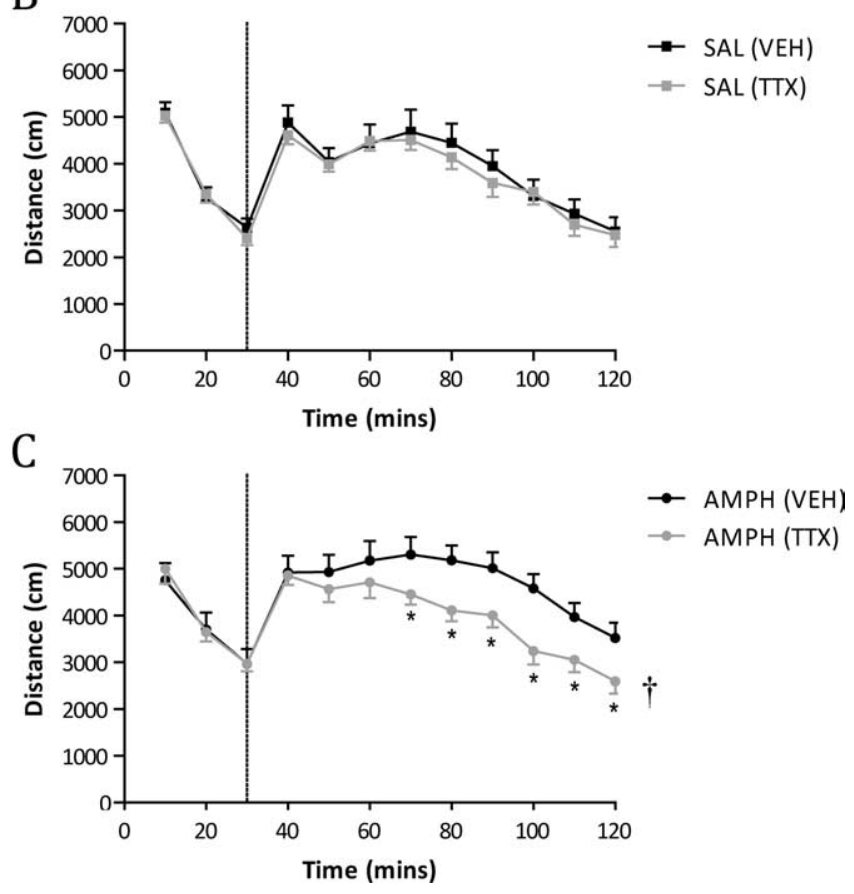

Figure 6. Bilateral vHipp inactivation by TTX $(1 \mu \mathrm{M})$ normalizes the aberrant locomotor response to amphetamine $(1.5 \mathrm{mg} / \mathrm{kg}$, i.p.) observed after sensitization. $\boldsymbol{A}$, Repeated amphetamine administration (AMPH) induced an augmented response to a subsequent amphetamine challenge compared with repeated saline-treated (SAL) rats. $\boldsymbol{B}, \boldsymbol{C}$, Inactivation of the vHipp by TTX did not affect psychostimulant-induced locomotion in SAL rats $(\boldsymbol{B})$, but significantly attenuated the augmented locomotor response to amphetamine in sensitized rats $(\boldsymbol{C})$. 'Significant group effect of treatment; *treatment interactions across time ( $p<0.05,2$-way ANOVA Tukey post hoc; $n=11-12$ rats per group; error bars represent SEM). VEH, Vehicle.

exploratory behavior between the groups, and thus the behavioral consequence of the augmented DA neuron activity is only revealed after amphetamine administration.

The model advanced here, that the behavioral sensitization to repeated amphetamine administration may be attributed to vHipp-induced enhancement of baseline DA neuron population activity, is consistent with a number of observations in amphetamine- and/or cocaine-sensitized rats. For example, a number of studies have reported an increased glutamatergic drive in psychostimulant-sensitized rats (Karler et al., 1991, 1994; Pierce et al., 1996). Thus, intra-Acb administration of the AMPA antagonist CNQX (6-cyano-7-nitroquinoxaline-2,3-dione) attenuates the expression of behavioral sensitization to cocaine (Pierce et al., 1996). Further evidence for an increased glutamatergic tone to the Acb is the observation of altered synaptic morphology in the Acb of sensitized rats. Thus, repeated psychostimulant administration induces a robust alteration in the spine density of medium-spiny neurons in the Acb that is localized to the distal dendrites, which largely receive extrinsic glutamatergic input (Li et al., 2004). Consequently, we propose that the purported increased glutamatergic drive to the Acb in sensitized rats arises, at least in part, from the ventral hippocampus. Indeed, we now demonstrate that repeated amphetamine administration increases both the average firing rate and the patterned activity of vHipp neurons.

The mechanism by which repeated amphetamine administration alters hippocampal output is not clear; however, there is significant evidence demonstrating a critical role of DA in hippocampal transmission. Thus, LTP is an index of synaptic strength and prominent form of signaling in the hippocampus and is strongly dependent on DA. More specifically, late-phase LTP is blocked by dopamine $\mathrm{D}_{1}$ receptor antagonists and is absent in $D_{1}$ receptor knock-out mice, whereas $D_{1}$ receptor activation leads to an enhancement of hippocampal LTP (Frey et al., 1990, 1991; Matthies et al., 1997; Granado et al., 2008). As such, it is possible that repeated psychostimulant-induced DA stimulation in the ventral hippocampus of sensitized rats induces an augmented hippocampal output in the form of LTP. Indeed, we have previously demonstrated the occlusion of vHipp-Acb LTP after repeated cocaine administration (Goto and Grace, 2005b). Interestingly, this effect was not observed after repeated amphetamine administration; rather, LTP was equally induced in amphetamine and saline-pretreated animals, whereas the ability of mPFC stimulation to reverse LTP was attenuated.

Taken as a whole, the present study demonstrates that the augmented responsivity to psychomotor stimulants observed in amphetamine-sensitized rats is likely attributable to an increase in tonic DA transmission secondary to augmented activity within the ventral hippocampal. Moreover, an augmentation of vHipp drive was also found in an animal developmental model of schizophrenia, in which endogenous vHipp overdrive also leads to aberrant DA signaling (Lodge and Grace, 2007). Such an understanding of the functional interactions among these systems and how pathology within these circuits affects central reward processing is critical to gaining a better understanding of the pathophysiology underlying drug abuse, and may provide novel pharmacotherapeutic approaches to its treatment.

\section{References}

Badiani A, Browman KE, Robinson TE (1995) Influence of novel versus home environments on sensitization to the psychomotor stimulant effects of cocaine and amphetamine. Brain Res 674:291-298.

Berridge KC, Robinson TE (1998) What is the role of dopamine in reward: hedonic impact, reward learning, or incentive salience? Brain Res Rev 28:309-369.

Einhorn LC, Johansen PA, White FJ (1988) Electrophysiological effects of cocaine in the mesoaccumbens dopamine system: studies in the ventral tegmental area. J Neurosci 8:100-112.

Floresco SB, Todd CL, Grace AA (2001) Glutamatergic afferents from the hippocampus to the nucleus accumbens regulate activity of ventral tegmental area dopamine neurons. J Neurosci 21:4915-4922.

Floresco SB, West AR, Ash B, Moore H, Grace AA (2003) Afferent modulation of dopamine neuron firing differentially regulates tonic and phasic dopamine transmission. Nat Neurosci 6:968-973.

Frey U, Schroeder H, Matthies H (1990) Dopaminergic antagonists prevent long-term maintenance of posttetanic LTP in the CA1 region of rat hippocampal slices. Brain Res 522:69-75.

Frey U, Matthies H, Reymann KG, Matthies H (1991) The effect of dopaminergic D1 receptor blockade during tetanization on the expression of long-term potentiation in the rat CA1 region in vitro. Neurosci Lett 129:111-114.

Goto Y, Grace AA (2005a) Dopaminergic modulation of limbic and cortical drive of nucleus accumbens in goal-directed behavior. Nat Neurosci 8:805-812. 
Goto Y, Grace AA (2005b) Dopamine-dependent interactions between limbic and prefrontal cortical synaptic plasticity in the nucleus accumbens: disruption by cocaine sensitization. Neuron 47:255-266.

Grace AA (1991) Phasic versus tonic dopamine release and the modulation of dopamine system responsivity: a hypothesis for the etiology of schizophrenia. Neuroscience 41:1-24.

Grace AA, Bunney BS (1983) Intracellular and extracellular electrophysiology of nigral dopaminergic neurons - 1. Identification and characterization. Neuroscience 10:301-315.

Grace AA, Bunney BS (1984) The control of firing pattern in nigral dopamine neurons: burst firing. J Neurosci 4:2877-2890.

Grace AA, Floresco SB, Goto Y, Lodge DJ (2007) Regulation of firing of dopaminergic neurons and control of goal-directed behaviors. Trends Neurosci 30:220-227.

Granado N, Ortiz O, Suárez LM, Martín ED, Ceña V, Solís JM, Moratalla R (2008) D1 but not D5 dopamine receptors are critical for LTP, spatial learning, and LTP-induced arc and zif268 expression in the hippocampus. Cereb Cortex 18:1-12.

Henry DJ, Greene MA, White FJ (1989) Electrophysiological effects of cocaine in the mesoaccumbens dopamine system: repeated administration. J Pharmacol Exp Ther 251:833-839.

Hinson RE, Poulos CX (1981) Sensitization to the behavioral effects of cocaine: modification by pavlovian conditioning. Pharmacol Biochem Behav 15:559-562.

Jung MW, Wiener SI, McNaughton BL (1994) Comparison of spatial firing characteristics of units in dorsal and ventral hippocampus of the rat. J Neurosci 14:7347-7356.

Kalivas PW, Stewart J (1991) Dopamine transmission in the initiation and expression of drug- and stress-induced sensitization of motor activity. Brain Res Rev 16:223-244.

Karler R, Calder LD, Turkanis SA (1991) DNQX blockade of amphetamine behavioral sensitization. Brain Res 552:295-300.

Karler R, Calder LD, Bedingfield JB (1994) Cocaine behavioral sensitization and the excitatory amino acids. Psychopharmacology 115:305-310.

Legault M, Wise RA (1999) Injections of $N$-methyl-D-aspartate into the ventral hippocampus increase extracellular dopamine in the ventral tegmental area and nucleus accumbens. Synapse 31:241-249.

Li Y, Acerbo MJ, Robinson TE (2004) The induction of behavioural sensitization is associated with cocaine-induced structural plasticity in the core (but not shell) of the nucleus accumbens. Eur J Neurosci 20:1647-1654.

Lisman JE, Grace AA (2005) The hippocampal-VTA loop: controlling the entry of information into long-term memory. Neuron 46:703-713.

Lodge DJ, Grace AA (2005) Acute and chronic corticotropin-releasing factor 1 receptor blockade inhibits cocaine-induced dopamine release: correlation with dopamine neuron activity. J Pharmacol Exp Ther 314:201-206.
Lodge DJ, Grace AA (2006a) The laterodorsal tegmentum is essential for burst firing of ventral tegmental area dopamine neurons. Proc Natl Acad Sci U S A 103:5167-5172.

Lodge DJ, Grace AA (2006b) The hippocampus modulates dopamine neuron responsivity by regulating the intensity of phasic neuron activation. Neuropsychopharmacology 31:1356-1361.

Lodge DJ, Grace AA (2007) Aberrant hippocampal activity underlies the dopamine dysregulation in an animal model of schizophrenia. J Neurosci 27:11424-11430.

Luo AH, Georges FE, Aston-Jones GS (2008) Novel neurons in ventral tegmental area fire selectively during the active phase of the diurnal cycle. Eur J Neurosci 27:408-422.

Matthies H, Becker A, Schröeder H, Kraus J, Höllt V, Krug M (1997) Dopamine D1-deficient mutant mice do not express the late phase of hippocampal long-term potentiation. Neuroreport 8:3533-3535.

Moses SN, Sutherland RJ, McDonald RJ (2002) Differential involvement of amygdala and hippocampus in responding to novel objects and contexts. Brain Res Bull 58:517-527.

Paxinos G, Watson C (1986) The rat brain in stereotaxic coordinates. Sydney: Academic.

Pierce RC, Kalivas PW (1997) A circuitry model of the expression of behavioral sensitization to amphetamine-like psychostimulants. Brain Res Rev 25:192-216.

Pierce RC, Bell K, Duffy P, Kalivas PW (1996) Repeated cocaine augments excitatory amino acid transmission in the nucleus accumbens only in rats having developed behavioral sensitization. J Neurosci 16:1550-1560.

Post RM, Rose H (1976) Increasing effects of repetitive cocaine administration in the rat. Nature 260:731-732.

Post RM, Lockfeld A, Squillace KM, Contel NR (1981) Drug-environment interaction: context dependency of cocaine-induced behavioral sensitization. Life Sci 28:755-760.

Robinson TE, Berridge KC (1993) The neural basis of drug craving: an incentive-sensitization theory of addiction. Brain Res Rev 18:247-291.

Schultz W (1998) Predictive reward signal of dopamine neurons. J Neurophysiol 80:1-27.

Segal DS, Mandell AJ (1974) Long-term administration of D-amphetamine: progressive augmentation of motor activity and stereotypy. Pharmacol Biochem Behav 2:249-255.

Squire LR, Stark CEL, Clark RE (2004) The medial temporal lobe. Annu Rev Neurosci 27:279-306.

White FJ, Wang RY (1984) Electrophysiological evidence for A10 dopamine autoreceptor subsensitivity following chronic D-amphetamine treatment. Brain Res 309:283-292.

White IM, Whitaker C, White W (2006) Amphetamine-induced hyperlocomotion in rats: hippocampal modulation of the nucleus accumbens. Hippocampus 16:596-603. 